\title{
Malignant Intraductal Lesions in the Breast: Mini-Review
}

\author{
Shinya Tajima ${ }^{1 *}$, Ichiro Maeda ${ }^{1}$, Keiko Kishimoto ${ }^{2}$, Saeko Naruki ${ }^{1}$, Akira Endo ${ }^{1}$, Masatomo Doi ${ }^{1}$, \\ Motohiro Chosokabe ${ }^{1}$, Koichiro Tsugawa ${ }^{3}$, Masayuki Takagi ${ }^{1}$ and Junki Koike ${ }^{1}$ \\ ${ }^{1}$ Department of Pathology, Japan \\ ${ }^{2}$ Department of Radiology, Japan
}

${ }^{3}$ Department of Breast and Endocrine Surgery, Japan

*Corresponding author: Shinya Tajima, Mailing address: Department of Pathology, 2-16-1 Sugao, Miyamae-ku, Kawasaki city,

Kanagawa prefecture, 216-8511, Japan

\begin{tabular}{|c|c|}
\hline ARTICLE INFO & ABSTRACT \\
\hline Received: 慧 April 05, 2019 & Citation: Shinya Tajima, Ichiro Maeda, Keiko Kishimoto, Saeko Naruki, Akira Endo, et al., \\
\hline Published: 幽 April 15, 2019 & $\begin{array}{l}\text { Malignant Intraductal Lesions in the Breast: Mini-Review. Biomed J Sci \& Tech Res 17(1)- } \\
\text { 2019. BJSTR. MS.ID.002947. }\end{array}$ \\
\hline
\end{tabular}

\section{Review}

Malignant intraductal lesion of the breast is equal to Ductal carcinoma in situ (DCIS). And synonyms are Ductal intraepithelial neoplasia (DIN) and Intraductal carcinoma (IDC). The definition of DCIS is clonal proliferations of epithelial cells confined to ducts and lobules with a cohesive pattern and typically immunohistochemically E-cadherin positive [1]. The DCIS grade is divided into three scales as low grade, intermediate grade, high grade. Tavassoli advocated the concept of DIN. And DCIS should be called DIN although the name of DCIS is major and common. I agree with this concept because of the below reason. Usual mammary ducts and lobules maintain myoepithelial cells. In this status, bilayer structure between mammary epithelial cells and myoepithelial cells is kept normally. And there is some cell to cell communications between mammary epithelial cells and myoepithelial cells. However, in DCIS cases, some abnormalities occur in multiple each stages of cell to cell interaction. Then the mammary ducts are distended, and with that, myoepithelial cells are dilated. And finally disappear. Then, DCIS lesions might change to invasive lesions. In this situation, some microenvironment including apoptosis, matrix metallo-proteinase might concern closely.

From the above mentioned, cell to cell interaction between mammary epithelial cell and myoepithelial cell. Hence, the term of "Ductal intraepithelial neoplasia" imply the nuance of cell to cell communication. So, we think the word DIN is more appropriate than DCIS. Some molecular subtypes recognized in invasive carcinoma are also seen in DCIS. Luminal A (ER positive, HER2 negative) is about 70\%. Luminal B HER2 positive (ER positive, HER2 positive) is about $10-20 \%$. HER2 (ER negative, HER2 positive) is about 20 $30 \%$. And Triple negative (ER/PgR/HER2 negative) is about $5-10 \%$ [1]. Taking into consideration above things, triple negative cancer rate is low in DCIS. Hence, we think DCIS in small size is more curable than invasive cancer. DCIS is pathologically classified into six types of cribriform type, papillary type, micropapillary type, comedo type, solid type and clinging type. This classification is useful for recognizing DCIS for patho-histologically. However, sometimes it is difficult to discriminate benign ductal lesion and DCIS especially papillary type of DCIS. Hence, it is thought to be important to differentiate between benign papillary lesion of the breast and papillary type of DCIS of especially low-grade type.

To discriminate between benign and malignant lesion in breast papillary lesion, it is reported that the combination of high molecular weight cytokeratin (HWCK) of CK14 and estrogen (ER) immunostainings are useful [2-4]. In using these immunostainings, almost all the papillary lesions are diagnosed benign or malignant excluding apocrine papillary lesion. Because, if DCIS cases, CK14 will be negative and ER will reveal diffusely positive. On the other hand, benign papillary lesions will show mosaic positive pattern of CK14 and ER will not demonstrate diffuse positive pattern in immunohistochemistry. Furuya et al. [4] advocated the Differential Index using Allred Score: ([ER total score] + [MUC3 total score]) / ([CK5/6 total score] + [p63 total score]) [4]. If this score is less than 1 , it is thought that it is benign lesion. This formula is useful discriminating between benign and malignant papillary lesions, if 
CK14 and ER are not available. MUC3 immunostaining is thought to be useful and important when diagnosing the difficult breast papillary lesion [2,3]. Loss of myoepithelial cells in breast tumors are commonly thought to be malignant and invasive lesions.

In the past, Cserni $\mathrm{G}$ and Tramm $\mathrm{T}$ et al. reported that benign and non-invasive apocrine papillary lesions which demonstrate reduction and occasional complete loss of myoepithelial cells $[5,6]$. These lesions are thought to be benign lesion, however lacking myoepithelial cells. And it is thought that apocrine papillary lesions are special distinct lesions. Recently, Shinya $\mathrm{T}$ et al. reported that the two cases of "Non-apocrine papillary lesions lacking myoepithelial cells [7]." These lesions showed epithelial papillary proliferation with nuclear inverse polarity, absence of nuclear atypia lined by the fibrovascular core, and lack of myoepithelial cells. In immunostainings, CK14 and ER were both negative. Hence, they tried the differential index, and the lesions were at the most a tumor of uncertain malignant potential [7]. Someone indicate these breast lesions' name is too long, so, "Tajioma" might be suitable. Then, taking into consideration of these things, it might be thought that there is the breast papillary lesion between non-invasive and invasive lesion. We think that it might exist middle stage between in situ lesion and invasive lesion. In the future, the report of breast lesions lacking myoepithelial cells which behave as benign or at the most tumor of uncertain malignant potential (not equal to malignancy) will be increase.

\section{ISSN: 2574-1241}

DOI: 10.26717/BJSTR.2019.17.002947

Shinya Tajima. Biomed J Sci \& Tech Res

This work is licensed under Creative Commons Attribution 4.0 License

Submission Link: https://biomedres.us/submit-manuscript.php
In conclusion, discriminating between papillary type of DCIS and benign papillary lesion of the breast is sometimes difficult and challenging. Hence, we must diagnose the breast papillary type of DCIS attentively, even though it might be disturbing case.

\section{References}

1. Hicks, Lester (2012) Ductal Carcinoma In Situ. In Diagnostic Pathology Breast 5: 16-27.

2. Shinya T, Ichiro M, Motohiro C, Keiko K, Takafumi O, et al. (2018) Breast Benign Papillary Lesions: Mini-review. Clin Pathol and Res J 2(1): 000111.

3. Shinya T, Ichiro M, Motohiro C (2019) Atypical Ductal Lesion in the breast: Review 1(2): ABEB.MS.ID.000508.

4. Furuya C, Kawano H, Yamanouchi T, Oga A, Ueda J, et al. (2012) Combined evaluation of CK5/6, ER, p63, and MUC3 for distinguishing breast intraductal papilloma from ductal carcinoma in situ. Pathol Int 62: 381-390.

5. Tramm T, Kim JY, Tavassoli FA (2011) Diminished Number of Complete Loss of Myoepithelial Cells Associated with Metaplastic and Neoplastic Apocrine Lesions of the Breast. Am J Surg Pathol 35(2): 202-211.

6. Cserni G (2008) Lack of myoepithelium in apocrine glands of the breast does not necessarily imply malignancy. Histopathology 52(2): 253-255.

7. Shinya T, Ichiro M, Yoshio A, Kazama A, Koizumi H, et al. (2018) Nuclear inverse polarity papillary lesions lacking myoepithelial cells: A report of two cases. Pathol Int 68(1): 36-40.



